1 Dobbs HS. Survivorship of total hip replacements. $f$ Bone foint Surg [Br] 1980;62:168-73.

2 Paterson JMH, Fulford PC, Denham RA. Loosening of the femoral component after total hip replacement. $\mathcal{F}$ Bone $\mathcal{J}$ oin Surg [Br] 1986;68:392-7.

3 Lee AJC, Ling RSM. Improved cementing techniques. American Academy of Orthopaedic and Surgical Instruments Course Lecture 1981;30:407-13.

4 Weber FA, Charnley J. A radiological study of fractures of acrylic cement in relation to the stem of a femoral head prosthesis. f Bone foint Surg [Br] 1975;57:297-301.

5 Ling RSM, Halawa M, Lee AJC, Vangala SS. Total hip replacement using the Exeter prosthesis. I Bone foint Surg [Br] 1981;63:283.

\section{Halothane hepatitis in children}

SIR,-Dr James Mayhew's recent letter (8 August, p 392), in which he criticised an article by myself and coworkers on halothane hepatitis in children $(9$ May, $p$ 1209), contains a serious factual inaccuracy that cannot be allowed to pass unchallenged.

Dr Mayhew states that detection of antibodies reacting with halothane induced liver antigens "is not specific," by which he means, presumably, that such antibodies are not restricted to patients with halothane hepatitis. As even a cursory examination of published reports should show, this is untrue. ${ }^{1}$ A wide range of control serum samples have been tested for the presence of such antibodies. These include serum samples from patients who have received halothane anaesthetics without developing liver damage and from patients who have developed liver damage attributable to causes other than halothane after receiving a halothane anaesthetic - that is, patients with serological markers of recent infection with hepatitis $A$ or B virus. The antibodies have been detected in none of the control samples tested to date. Thus serological testing for antibodies to halothane induced liver antigens seems to be a promising and useful aid to diagnosis of halothane hepatitis.

It would be a pity if Dr Mayhew's letter were to detract from this finding, or indeed the major point of the paper-namely, that current evidence firmly indicates the existence of halothane hepatitis as a clinical entity in children, the incidence of which is unknown at present.

It should also be noted that various methods have been described for detecting the antibodies. The antibody tests referred to in the paper are an enzyme linked immunosorbent assay (ELISA) method and a recently developed immunoblotting technique, and not the earlier (and much less objective) induced cytotoxicity assay.

National Heart, Lung, and Blood Institute,

J G KENNA Bethesda,

Maryland 20892

1 Neuberger J, Kenna JG. Halothane hepatitis: a model of immune mediated drug hepatotoxicity. Clin Sci 1987;72: 263-70.

\section{A shocking American report with lessons for us all}

SIR,-Dr A E M McLean (12 September, p 671) challenges my view that trials of potential drugs in healthy subjects must always be ethically dubious. This statement does not imply that such studies are necessarily wrong, simply that they should raise doubts in the mind of the investigator as to whether they are ethically sound. I am surprised that he should regard such an opinion as astounding, especially in view of the well publicised death of a student volunteer taking part in a drug trial in recent years. Moreover, my view is not idiosyncratic, but has the support of the Declaration of Helsinki and an international symposium on clinical trials in oncology, both of which I quoted in my leading article. ${ }^{12}$
As Dr McLean says, studies in human volunteers have a long and honourable history in medicine, but he and other investigators should recognise that such volunteers are altruistically giving up one of their human rights. The investigator is then in a special position of trust and must be honest with the volunteers, explaining fully the possible effects of the drug and providing for adequate follow up.

By definition, volunteers are not pressed men. It seems to me that for investigators to choose their own students as subjects for experiments betrays a disregard of human rights. How can they refuse to take part and still maintain the good will of their supervisor?

T J HAMBLIN Royal Victoria Hospital,

1 Worid Medical Association. Human Experimentation. Code of ethics of the World Medical Association. Declaration of Helsinki. BrMed J 1986;293:173.

2 Durrya $D$. The ethical approach to phase 1 clinical trials in oncology. Drugs Exp Clinical Research 1986;12:21-22.

SIR,-While I (and I suspect many other people concerned with clinical research) agree with Professor T J Hamblin's sentiments about details published in the report from America cited in his article (11 July, p 73), I cannot agree with his condemnation of all investigations entailing normal people and particularly phase I clinical trials that include healthy volunteers.

As I am sure Professor Hamblin is aware, a report from the Royal College of Physicians has just been published dealing with research on healthy volunteers, ${ }^{1}$ guidelines for volunteer studies within the pharmaceutical industry have been available since $1970,{ }^{2}$ and the Declaration of Helsinki has been updated. These reports have recommendations and guidelines on performing clinical studies in volunteers outside medical establishments. The report from the Royal College of Physicians addresses itself clearly to some of Professor Hamblin's comments. I would like to address three points.

Firstly, phase I volunteer studies have become an integral part of the development of new medicines, contributing essential information on pharmacokinetics and metabolism (to put them into context with animal toxicological studies) and on pharmacodynamic dose response studies, from which an appropriate dose may be estimated for treating patients in clinical trials. Elements of safety may also be assessed.

Secondly, employees of a firm or institution are admirable subjects for phase I volunteer studies. In our own clinical pharmacology unit subjects are truly volunteers in that there is no coercion or intended duress for people to participate. The use of a known pool of volunteers must further reduce the already very small risk of phase I studies because medical backgrounds, etc, are well known. Furthermore, "informed consent" is real when volunteers are fully briefed and also generally knowledgeable about new compounds, even having worked with them themselves in some cases.

Thirdly, the regulation of research entailing healthy volunteers is considered at length in the report by the Royal College of Physicians. Currently, opinion among clinical pharmacologists concerned with phase I studies favours regulation on a voluntary basis. Interested parties seem to be attempting to gather information from institutions performing clinical pharmacology using volunteers in preparation for deciding the best methods of "voluntary control." Ethics committees are likely to play a prominent part in implementing any such controls.

Last year in our clinical pharmacology unit some 200 people volunteered for our various studies. All studies were performed according to our guidelines, which are based on the Association of the British Pharmaceutical Industry's report and the Royal College of Physicians report, incorporate the principles of the Declaration of Helsinki, and state that all protocols should be agreed by an ethics committee. Thus I believe that self regulation exists for us at ICI and over the years has reflected the need to put the health and welfare of our volunteers first, in that no major and few minor untoward effects have occurred. Professor Hamblin does not say what regulation he would like to see for volunteer studies, perhaps governmental, but before suggesting this I hope that he will heed that guidelines such as our own are in use.

Clinical Pharmacology Unit,

Imperial Chemical Industries plc

Pharmaceuticals Division,

Cheshire SK 10 4TG

1 Royal College of Physicians Working Party. Research on healthy volunteers. I $R$ Coll Physicians Lond 1986;20:3-17.

2 Association of the British Pharmaceutical Industry. Report of the commitree to investigate medical experiments on staff volunteers. commitree to investigate medical experiments on staff volunteers.
London: Association of the British Pharmaceutical Industry, 1970.

\section{General practitioners' management of acute} myocardial infarction and cardiac arrest

SIR,-Dr John M Rawles provides an informative insight into the actual and potential role of the general practitioner in providing advanced cardiac life support when patients most require it-that is, at the scene of their infarct. Of all patients who die from acute myocardial infarction, $70 \%$ do so within the first two hours of infarction, usually out of hospital.

Most of the doctors in Dr Rawles's study thought that they would appreciate additional practice and tuition in cardiopulmonary resuscitation, and it is only with the advent of the Resuscitation Council (UK) that such teaching has become standardised. As far as I am aware, there are only two courses teaching advanced cardiac life support in this country, both of them open to doctors from throughout the United Kingdom. One is at the Central Middlesex Hospital and is organised by $\mathrm{Mr}$ Sapal Tachakra, and the other is here at St Bartholomew's Hospital.

The Resuscitation Council is considering standardising these courses, and certification for doctors working in emergency medicine would be a progressive step in line with the regulations in the United States. The Royal College of Physicians has, in its recent report, suggested standards for the provision and teaching of advanced cardiac life support. General practitioners should be at the forefront of the provision of advanced cardiac life support to their patients, who are often in the greatest need.

St Bartholomew's Hospital,

DAVID V SKINNER London EC1A 7BE

\section{Children and careers}

SIR,-Like Dr Yvonne Begley (5 September, p 604), I wish to combine being a successful, caring doctor with leading a close family life, and I am lucky enough to have a husband who shares this vision. I would like to point out, however, several ways in which this is made difficult.

I have recently applied for the part time senior registrar scheme. Firstly, this is not a flexible scheme. Applications are invited only once a year, and the cumbersome process, which entails a national competition as well as local interviews, 